\title{
Cloud Computing in Agricultural Enterprises in Slovakia
}

Anna Látečková, Michaela Trnková

Department of Accounting, Faculty of Economics and Management, Slovak University of Agriculture in Nitra, Slovak Republic

\begin{abstract}
We are currently making great strides in the field of ICTs, which is associated with the availability of other larger volumes of information any species. There are problems with their analysis, storage, as well as security in companies. The aim of the paper was to focus on the agricultural sector in terms of innovation. In the presented article we deal with the issue of cloud computing and its use in management in agricultural enterprises in Slovakia. We characterize cloud computing, its advantages and disadvantages, as well as the current use of this service by agricultural entreprises in Slovakia. We used the method of questionnaire survey and personal interview to investigate the above problems. We also focused on the study of cloud computing and related issues from available foreign sources. The results show that agricultural enterprises in Slovakia use cloud computing services less with comparing to the countries of EU.
\end{abstract}

\section{Keywords}

Agriculture enterprise, cloud computing, information.

Látečková, A. and Trnková, M. (2021) "Cloud Computing in Agricultural Enterprises in Slovakia", AGRIS on-line Papers in Economics and Informatics, Vol. 13, No. 2, pp. 87-95. ISSN 1804-1930. DOI 10.7160/aol.2021.130207.

\section{Introduction}

The development of ICT in business increases the dependence of enterprises on their use and managers must pay an necessary attention of this. ICT penetration also influences agricultural enterprises (Szabo et al., 2017). Their development influences economic environment and ranks among factors of business prosperity and competitiveness. Nowadays, it is not possible to manage enterprises and take professional decisions without information and using of ICT (Bolek et al., 2018). Some professionals consider cloud computing to be a significant advance in the area of development of computing technology over the last decade (Rajaraman, 2014). It is a new generation of information technology that integrates grid and cluster computing, virtualization, distributed processing, and computing (Sui and Sui, 2018). Cloud computing is a model that provides convenient network access to shared configurable computing resources on demand, which can be quickly provided and released with minimal effort in the area of management or interact from the service provider (Mell and Grance, 2011). The goal of cloud computing is to deliver applications over the Internet using hardware and software existing in data centers that provide these services in a transparent manner without the user needing to know the details of the underlying software and hardware. It offers cost-effective development of scalable web applications on a highly available fault-tolerant infrastructure (Wazzan and Fayoumi, 2012). Cloud computing is used for efficient data processing to make better decisions. It is an affordable, scalable and highly available platform technology (Tan, 2016). Many companies are interested in moving from their old system to a cloud computing system, with a view to minimizing the cost of using computing resources (Amanatullah et al., 2013). Cloud computing is a way to integrate a stateof-the-art background computing infrastructure to provide computing services to a large number of users (Goraya and Harjinder, 2015).

Choosing the right service model is a crucial success factor for a business. Therefore, it is necessary to understand what each model involves, what responsibility the cloud service provider as well as the consumer himself has. There are 3 cloud service models: Software as a Service (SaaS), Platform as a Service (PaaS), Infrastructure as a Service (IaaS) (Figure 1).

SaaS is the provider's applications that run in a cloud infrastructure, and these applications are accessible 


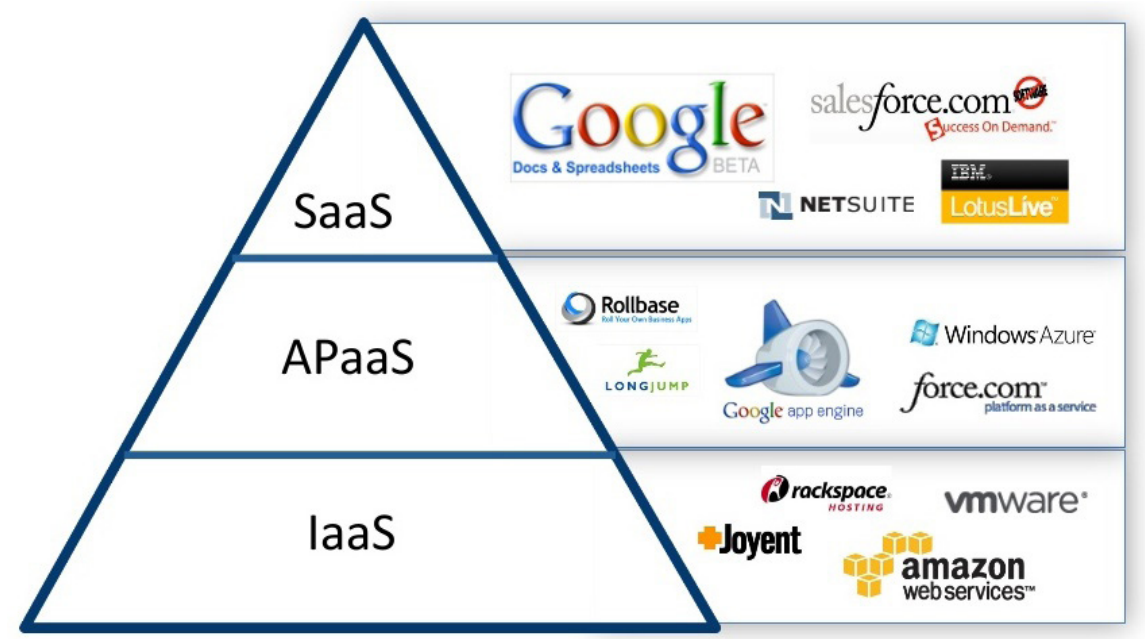

Source: Gartner (in Schalk 2010)

Figure 1: Examples of cloud computing services in single modules.

to the consumer from various client devices either through a web browser or through a programming interface. The provider manages the entire infrastructure, networks, servers, operating systems, storage, as well as the applications themselves. The consumer has the option to configure only some user-specific application parameters. PaaS provides the ability to deploy consumer-created applications to the cloud infrastructure. With PaaS, the provider also manages the cloud infrastructure. However, in addition to the possibility of setting the application parameters, the consumer also has control ver the entire application. With IaaS, the consumer also does not manage the cloud infrastructure, but has control over the operating systems, storage and deployed applications. Limited control over selected network components is also possible (Mell and Grance, 2011). Data as a Service (DaaS) is less talked about compared to the above layers, as many vendors currently offer cloud services in one or all of these layers. Given that people in the research field are interested in using the cloud, there is great interest in the availability of data as a service, especially for geographic data. It is thus the provision of valuable data as a service over the Internet on the basis of payment for its use (Patil et al., 2012).

Cloud computing includes three types of deployment models: public cloud, private cloud, and hybrid cloud. The public cloud offers services to every consumer over the Internet, which means that the cloud infrastructure is owned by a specific organization that sells services to the public. Private cloud offers services to selected customers, which means that the cloud infrastructure is owned by one organization, which manages it itself.
The hybrid cloud is a combination of public and private cloud; offers services from both public and private sources (Wazzan and Fayoumi, 2012). Many companies are implementing private clouds on their premises due to distrust of data security. With a private cloud, an enterprise can design, develop, and implement a customized cloud service and have complete control over data and other security issues, which is not possible in a public cloud (Wang, Rashid and Chuang, 2011).

Hori, Kawashima and Yamazaki (2010) report the following benefits of cloud computing:

- lower start-up costs,

- unrestricted allocation of resources on request,

- maintenance and updates are performed in the background,

- easy and rapid development, including cooperation with other cloud systems,

- more opportunities for the development of global services.

Patel and Patel (2013) include to the benefits of cloud computing its easy service management (there are no worries about procuring of licences, hardware, data center operations), scalability (easy extensibility of the service with new users), device and location independence (the way of accessing to the cloud can be your computer, someone else's computer, smart phone or solar powered touch pad). Abdalla and Varol (2019) also see certain issues with cloud storage services, such as control, security, support, performance and vendor blocking. Cloud computing plays an important role 
in the agricultural sector. With the introduction of the latest technologies, management is very simple. Cloud computing facilitates the storage, management, access and dissemination of agricultural information quickly and at low cost (Goraya and Harjinder, 2015). In the modern era of cloud computing technology, it is very useful to centralize an agricultural database (soil, weather, research, crops, farmers, agricultural marketing, fertilizer and pesticide information) in the cloud (Choudhary, Jadoun and Mandoriya, 2016). Cloud computing enables farms to provide all necessary services at affordable costs (Patil et al., 2012).

With the growing use of mobile devices and the development of wireless technologies, cloud computing has become a widely used model for providing services over the Internet (Alqahtani and Arishi, 2020). Mobile cloud computing is currently the primary element of research direction in mobile applications (Hao et al., 2018). Mobile cloud computing offers several benefits to the agricultural sector. Without worrying about investing in hardware and software, farmers can send their requests for specific data via cloud services using their mobile phones and internet connection. The cloud service provider processes these requests and sends back the results to clients (Athmaja and Hanumanthappa, 2016). The integration of cloud computing into the mobile environment also provides other benefits, such as longer battery life or lower processing load (Alonso-Monsalve, Garcia-Carballeira and Calderon, 2018). Involving cloud computing in the agricultural sector results in efficiently higher production, cost control, performance monitoring, and the like (Nanami and Gonen, 2020).

Mobile cloud computing is also important in the field of accounting processing. There are many applications that create invoices, track income and expenses, generate financial statements and other.

\section{Materials and methods}

The main goal of this article is to present the results of research in the field of cloud computing, specifically its use in agricultural enterprises in Slovakia. We specify the main goal in more detail into sub-goals, which are:

1. clarification of cloud computing issues,

2. finding out the measure of use of cloud computing in agricultural enterprises in Slovakia,
3. introducing the advantages and disadvantages of using cloud computing based on the answers of respondents,

4. comparison of selected aspects of the solved problem with EU countries.

Primary data are obtained by the questionnaire method. Due to the scientific research activities of our university (SPU in Nitra) and solved research tasks at the Department of Accounting, we focused on agricultural enterprises. The article presents partial results of the research project VEGA 1/0489/15 "Increasing the effectiveness of managers' decision-making with the support of information systems and accounting" in the period of years 2015-2018 and research activities 2019-2020. We examined the issue of cloud computing in more detail using the questionnaire method. The compiled questionnaire was available online, where we received answers from 73 respondents (enterprises). We used the MS EXCEL spreadsheet processor to evaluate the questionnaire. In addition to the questionnaire, the following methods are also used: analysis, synthesis, selection, comparison, mathematical-statistical and graphical methods. We also used the method of guided interview, where we consulted supplementary questions with managers of selected enterprises. Then, we focused on the study of cloud computing and related issues from available foreign sources.

\section{Results and discussion}

Information has long been one of the important factors in increasing the enterpise's competitiveness in the market. That is why it is important for enterprises to pay increased attention to innovations in the field of ICTs, as these are currently the ones that greatly influence theirs market position.

Based on the published questionnaire, we received answers from 73 respondents. According to the number of employees, we speak of small and medium-sized enterprises, where $69.86 \%$ stated the number of employees less than 10 ; $8.22 \%$ employ $11-50$ employees and $21.92 \%$ have a number of employees in the range of 51-250.

We were mainly interested in answers to questions about the use of cloud computing in these enterprises. Based on the obtained answers, we introduce the following results.

Answers od respondents to the question 
about the availability of data from the corporate information system differ. $54.79 \%$ of respondents stated that access to data is possible only from individual computers in the enterprise. $19.18 \%$ claim that they also have remote access in the enterprise, which also allows them to work from home. $13.70 \%$ of respondents also use external storage (cloud computing) and $17.81 \%$ said "I don't know" (Figure 2).

Businesses that do not use cloud computing services have their own information system with their own database. These enterprises need employees specializing in the care of ICTs which in turn increases labor and personnel costs.

In cloud computing, the enterprise does not own an information system or database, but leases software and data storage from the company that provides these services. Consequently, there are no costs for employees who would take care of ICTs. But there are costs for cloud computing services.

Štětka, M. (2014) states that cloud computing enables small and medium-sized enterprises to become competitive, given its scalability and operating costs. For comparison - their research in the Czech Republic states that only $5 \%$ of IT professionals use cloud services and $10 \%$ plan to move to the cloud in the near future. He also gives figures from the most virtualized market in the world, from Australia, where up to $54 \%$ of entrepreneurs use active cloud computing and $25 \%$ are considering using it.

The situation is different in the environment of Slovak enterprises. $69.86 \%$ of agricultural enterprises use online communication with other entities. It is mainly about online communication, data transfer with the financial administration, health and social insurance company. They are followed by banks, suppliers and customers. $53.42 \%$ of respondents indicated the operation of the company's website (Figure 3).

The use of an Internet connection for e-mail communication is a matter of course for all 73 respondents. This is the most common way to use cloud computing over a period of several years. This is also confirmed by Eurostat research for the period 2014, 2016 and 2018, when on average $67 \%$ of EU-28 enterprises also put e-mail communication in the first place (Figure 4).

A more detailed use of cloud computing services by enterprises in individual countries is shown in Figure 5.

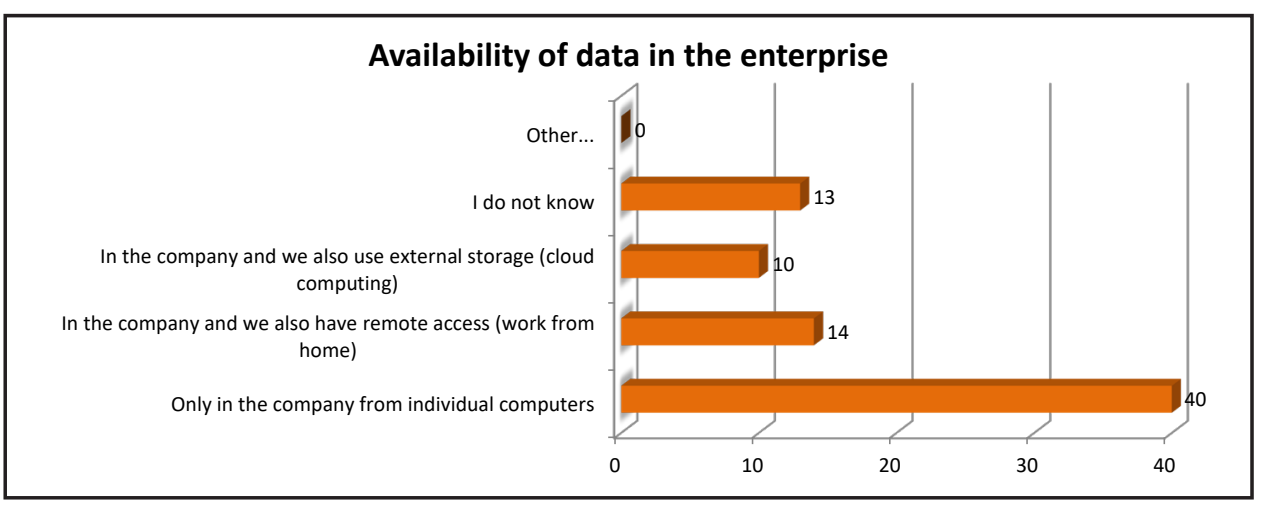

Source: author's calculations

Figure 2: Question no. 9 Data from your corporate information system is accessible.

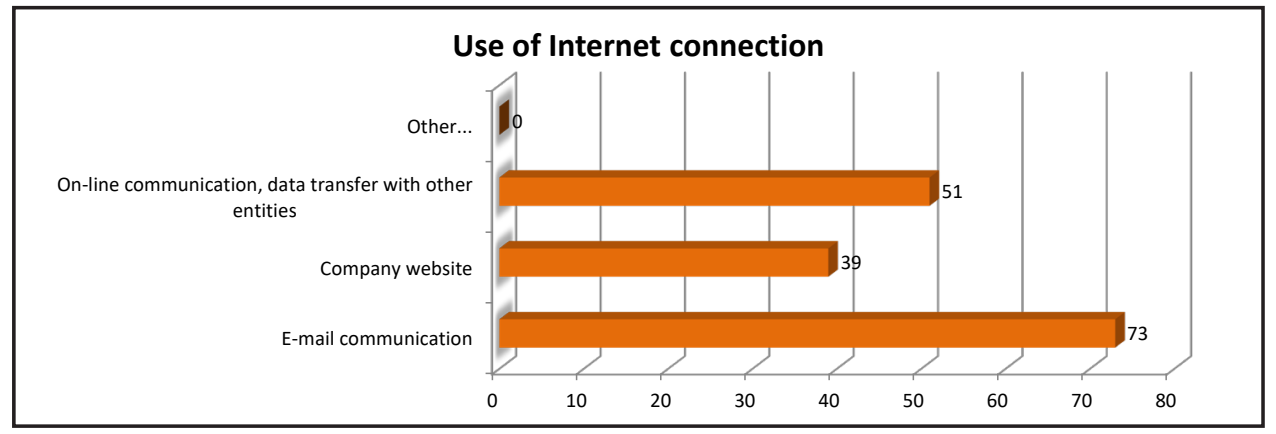

Source: author's calculations

Figure 3: Question no. 7 For what purposes do you use an internet connection in your company? 


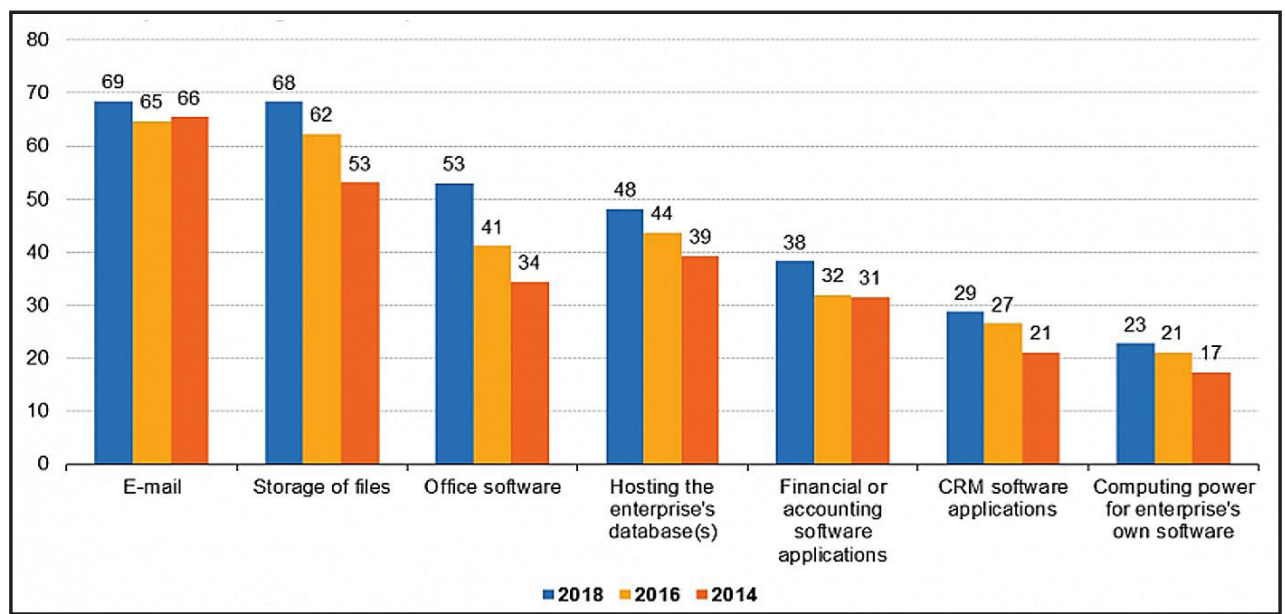

Source: Eurostat (2020)

Figure 4: Use of cloud computing services in enterprises of EU-28 by purpose - 2014, 2016 and 2018 ( $\%$ of enterprises using the cloud).

\begin{tabular}{|c|c|c|c|c|c|c|c|c|}
\hline & $\begin{array}{l}\text { Use of cloud } \\
\text { computing }\end{array}$ & E-mail & Storage of files & Office software & $\begin{array}{l}\text { Hosting the } \\
\text { enterprise's } \\
\text { database(s) }\end{array}$ & $\begin{array}{l}\text { Financial or } \\
\text { accounting } \\
\text { software } \\
\text { applications }\end{array}$ & $\begin{array}{l}\text { CRM software } \\
\text { applications }\end{array}$ & $\begin{array}{l}\text { Computing } \\
\text { power for } \\
\text { enterprise's } \\
\text { own software }\end{array}$ \\
\hline & $\%$ enterprises & \multicolumn{7}{|c|}{$\%$ enterprises using the cloud } \\
\hline EU-28 & 26 & 69 & 68 & 53 & 48 & 38 & 29 & 23 \\
\hline Belgium & 40 & 71 & 71 & 59 & 55 & 41 & 40 & 33 \\
\hline Bulgaria & 8 & 73 & 64 & 56 & 58 & 28 & 26 & 20 \\
\hline Czechia & 26 & 77 & 64 & 56 & 36 & 33 & 21 & 17 \\
\hline Denmark & 56 & 74 & 69 & 58 & 55 & 52 & 41 & 37 \\
\hline Germany & 22 & 48 & 61 & 34 & 33 & 28 & 19 & 19 \\
\hline Estonia & 34 & 68 & 48 & 43 & 26 & 64 & 19 & 9 \\
\hline Ireland & 45 & 78 & 78 & 63 & 52 & 45 & 34 & 22 \\
\hline Greece & 13 & 68 & 61 & 48 & 43 & 20 & 22 & 22 \\
\hline Spain & 22 & 74 & 73 & 48 & 64 & 32 & 33 & 28 \\
\hline France & 19 & 65 & 77 & 46 & 63 & 32 & 35 & 20 \\
\hline Croatia & 31 & 82 & 65 & 54 & 47 & 44 & 17 & 24 \\
\hline Italy & 23 & 82 & 60 & 47 & 46 & 34 & 25 & 13 \\
\hline Cyprus & 27 & 82 & 66 & 60 & 32 & 31 & 27 & 19 \\
\hline Latvia & 15 & 64 & 41 & 41 & 48 & 46 & 19 & 8 \\
\hline Lithuania & 23 & 70 & 61 & 39 & 52 & 41 & 27 & 36 \\
\hline Luxembourg & 25 & 66 & 73 & 57 & 53 & 29 & 29 & 24 \\
\hline Hungary & 18 & 73 & 59 & 56 & 38 & 35 & 27 & 31 \\
\hline Malta & 37 & 81 & 73 & 64 & 42 & 28 & 26 & 23 \\
\hline Netherlands & 48 & 67 & 72 & 56 & 70 & 59 & 45 & 24 \\
\hline Austria & 23 & 58 & 67 & 38 & 30 & 17 & 21 & 20 \\
\hline Poland & 11 & 67 & 53 & 51 & 33 & 27 & 23 & 15 \\
\hline Portugal & 25 & 82 & 63 & 52 & 40 & 33 & 26 & 31 \\
\hline Romania & 10 & 77 & 60 & 52 & 50 & 50 & 0 & 31 \\
\hline Slovenia & 26 & 71 & 57 & 57 & 37 & 33 & 20 & 25 \\
\hline Slovakia & 21 & 83 & 60 & 60 & 39 & 44 & 26 & 25 \\
\hline Finland & 65 & 79 & 69 & 65 & 53 & 56 & 37 & 18 \\
\hline Sweden & 57 & 72 & 74 & 53 & 52 & 51 & 31 & 26 \\
\hline United Kingdom & 42 & 72 & 77 & 73 & 49 & 45 & 32 & 28 \\
\hline Norway & 51 & 78 & 77 & 61 & 65 & 60 & 40 & 32 \\
\hline Montenegro & 18 & 65 & 50 & 44 & 50 & 41 & 13 & 26 \\
\hline Serbia & 15 & : & : & : & : & : & : & : \\
\hline Turkey & 10 & 81 & 73 & 64 & 58 & 65 & 38 & 49 \\
\hline Bosnia and Herzegovina & 8 & 73 & 59 & 49 & 64 & 56 & 25 & 37 \\
\hline
\end{tabular}

Source: Eurostat (2020)

Figure 5: Use of cloud computing services in enterprises of EU-28 by purpose per a year 2018.

Businesses using cloud computing services cite online access to data from anywhere with an Internet connection as the biggest advantage. We can say that in today's globalized environment, this approach is almost everywhere where an entrepreneur or manager needs it, and the coverage of the Internet connection is constantly expanding to less developed areas. $10.96 \%$ of respondents agree on the other 2 advantages of cloud computing, namely in lower initial costs, as well as in the fact that updates and information security are handled by a company 
that provides cloud computing services (Figure 6).

On the contrary, $62.50 \%$ of respondents consider the biggest disadvantage of using cloud services to be the failure of the Internet connection, which will make it impossible to work with the data needed for decision-making and management. Only $37.50 \%$ fear data misuse and $25 \%$ data loss. $6.85 \%$ of respondents also identified increased operating costs as a disadvantage (Figure 7).

The fact that the loss of the Internet connection is a threat to enterprises using cloud computing is also confirmed by the Gartner company's analysis, which shows that two out of five enterprises are forced to close within five years of experiencing a major IT outage (Štětka, 2014).

In the following figure we can see a comparison of the use of cloud computing services by enterprises in individual EU countries in 2018 . The Slovak Republic is almost among the last countries with $21.10 \%$, which is also confirmed by the results of our research. Finland is the leader in the use of cloud services with $61.30 \%$. On the contrary, Bulgaria is the worst with $8.30 \%$ (Figure 8).

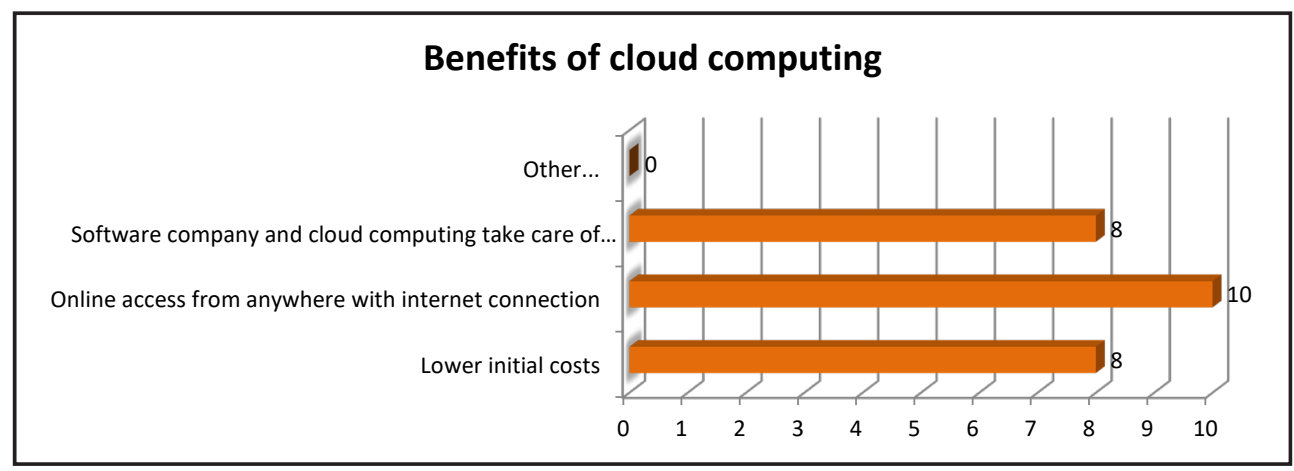

Source: author's calculations

Figure 6: Question no. 10 - If you use cloud computing, state its benefits.

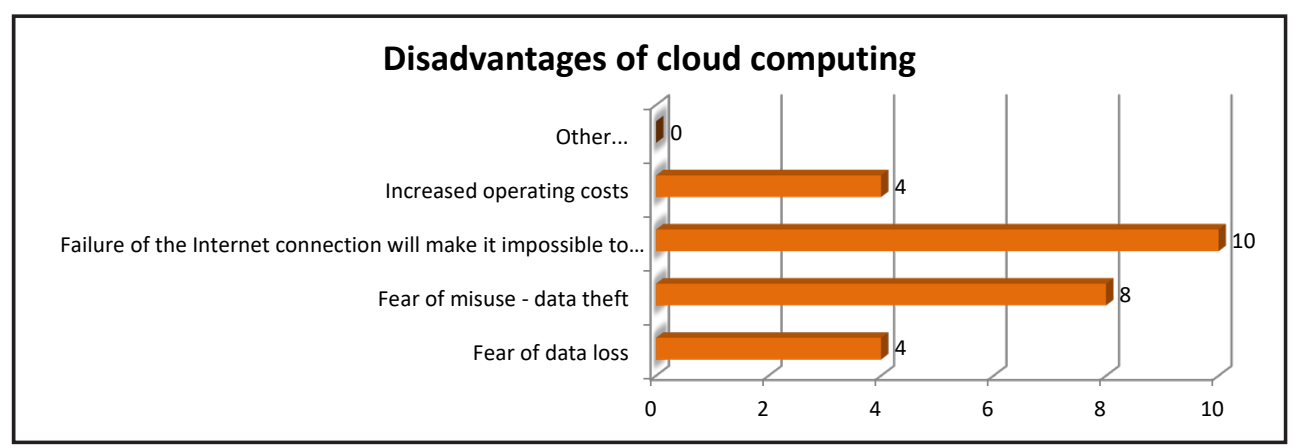

Source: author's calculations

Figure 7: Question no. 11 - If you use cloud computing, state its disadvantages

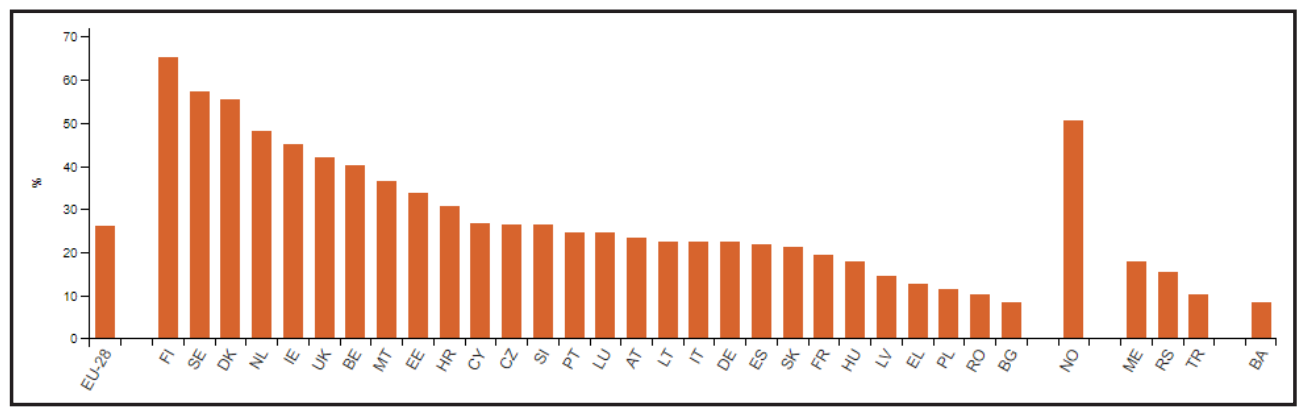

Source: author's calculations

Figure 8: Use of cloud computing services in the EU-28 per a year 2018 (\% of enterprises using the cloud). 


\section{Conclusion}

In the last decades, ICTs have been developing at a rapid pace. If a company wants to stay in the market, it needs to adapt to these changes. The introduction of ICTs in the area of farm management is a necessity. The requirements for recording and reporting data for the management needs of the managers themselves, as well as for various external entities, are growing. Today, we do not find an agricultural enterprise that does not have its information system handled automatically. The level of either computing technology or implemented software is in single enterprises various.

Based on the research, we came to the conclusion that agricultural enterprises in Slovakia still do not trust cloud computing. Most enterprises have their own information system with their own database. Businesses using cloud computing have cited online access to data as its biggest advantage. On the contrary, they consider the failure of the internet connection to be the biggest disadvantage, which will prevent them from working in the information system.

The SR has large reserves in the use of cloud computing services. Within the EU-28 countries, according to Eurostat, the SR ranks as high as 21 place in the use of cloud computing, where only $21 \%$ of enterprises use these services.

Based on the processed data, we obtained an overview of the state of use of cloud computing in agricultural enterprises in Slovakia. It is important to realize how much this issue needs to be addressed at this time.

The results of the research can be further used in a more detailed analysis of these problems with the application of mathematical and statistical methods. Using the Chi-square test of the square contingency, it is possible to examine the dependence between the qualitative features - the answers of the respondents to the individual questions of the questionnaire.

In our opinion, cloud computing is very promising for the future, which is confirmed by the opinions of foreign authors. The growth of the use of cloud computing services can be achieved by realizing more extensive and massive foreknowledging of managers and business owners about the possibilities of using cloud computing, its advantages and disadvantages. Poor awareness of new possibilities in the field of ICTs especially in the agricultural field, causes the lagging progress of these enterprises, which to a large extent also ultimately affects their competitiveness.

Corresponding authors

doc. Ing. Anna Látečková, PhD.

Department of Accounting, Faculty of Economics and Management

Slovak University of Agriculture in Nitra, Tr. Andreja Hlinku 2, 94976 Nitra, Slovak Republic

E-mail: anna.lateckova@uniag.sk

\section{References}

[1] Abdalla, P. A. and Varol, A. (2019) "Advantages to Disadvantages of Cloud Computing for Small-Sized Business", $7^{\text {th }}$ International Symposium on Digital Forensics and Security (ISDFS. ISBN 978-1-7281-2827-6. DOI 10.1109/ISDFS.2019.8757549.

[2] Alonso-Monsalve, S., García-Carballeira, F. and Calderón, A. (2018) "A heterogeneous mobile cloud computing model for hybrid clouds“, Future Generation Computer Systems, Vol. 87, pp. 651-666. ISSN 0167-739X. DOI 10.1016/j.future.2018.04.005.

[3] Alqahtani, S. M. and Arishi, H. (2020) "A Review on the Tools and Techniques for Effective Failure Detection and Prediction in Cloud Computing", International Transaction Journal of Engineering, Management, \& Applied Sciences \& Technologies, Vol. 11, No. 16, pp. 1-8. ISSN 2228-9860. DOI 10.14456/ITJEMAST.2020.315.

[4] Amanatullah, Y., Lim, Ch., Ipung, H. P. and Juliandri, A. (2013) "Toward Cloud Computing Reference Architecture: Cloud Service Management Perspective“, International Conference on ICT for Smart-Society (ICISS), pp 34-37. ISBN 2471-1233. DOI 10.1109/ICTSS.2013.6588059.

[5] Athmaja, S. and Hanumanthappa, M. (2016) "Applications of Mobile Cloud Computing and Big Data Analytics in Agriculture Sector - A Survey", International Journal of Advanced Research in Computer and Communication Engineering, Vol. 5, No. 2, pp. 33-38. ISSN 2319-5940. 
[6] Bolek, V., Kokles, M., Romanová, A. and Zelina, M. (2018) "Information Literacy of Managers: Models and Factors“, Journal of Business Economics and Management, Vol. 19, No. 5, pp. 722- 741. ISSN 1611-1699. DOI 10.3846/jbem.2018.6906.

[7] Choudhary, S. K., Jadoun, R. S. and Mandoriya, H. L. (2016) "Role of Cloud Computing Technology in Agriculture Fields“, Computer Engineering and Intelligent Systems, Vol. 7, No. 3, pp. 1-7. ISSN 2222-1719.

[8] Eurostat (2020) "Cloud computing - statistics on the use by enterprises", Dec. 2018. [Online]. Available: https://ec.europa.eu/eurostat/statistics-explained/index.php/Cloud_computing_-statistics_on_the_use_by_enterprises[Accessed: 23 Nov. 2020].

[9] Goraya, M. S. and Harjinder, K. (2015) "Cloud Computing in Agriculture“, HCTL Open International Journal of Technology Innovations and Research (IJTIR), Jul. 2015. [Online]. Available: http:// citeseerx.ist.psu.edu/viewdoc/download?doi=10.1.1.695.2449\&rep=rep1 \&type=pdf [Accessed: 23 Jul. 2020].

[10] Hao, J., Xian, M., Wang, H., Tang, F. and Xiao, P. (2018) "Mobile Cloud Computing: the State of Art, Application Scenarios and Challenges“, $4^{\text {th }}$ International Conference on Computational Intelligence \& Communication Technology (CICT). ISBN 978-1-5386-0886-9. DOI 10.1109/CIACT.2018.8480365.

[11] Hori, M., Kawashima, E. and Yamazaki, T. (2010) "Application of Cloud Computing to Agriculture and Prospects in Other Fields“, Fujitsu Scientific \& Technical Journal, Vol. 46, No. 4, pp. 446-454. ISSN 0016-2523.

[12] Mell, P. and Grance, T. (2011) "The NIST Definition of Cloud Computing“, Special Publication 800-145, Sep. 2011. [Online]. Available: https://nvlpubs.nist.gov/nistpubs/Legacy/SP/ nistspecialpublication800-145.pdf [Accessed: 23 Jul. 2020]. DOI 10.6028/NIST.SP.800-145.

[13] Namani, S. and Gonen, B. (2020) "Smart Agriculture Based on IoT and Cloud Computing",

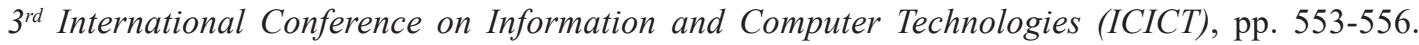
ISBN 978-1-7281-7283-5. DOI 10.1109/ICICT50521.2020.00094.

[14] Patel, R. and Patel, M. (2013) "Application of Cloud Computing in Agricultural Development of Rural India“, International Journal of Computer Science and Information Technologies, Vol. 4, No. 6, pp. 922-926. ISSN 0975-9646.

[15] Patil, V. C., Al-Gaadi, K. A., Buradar, D. P. and Madugundu, R. (2012) "Internet of Things (IoT) and Cloud Computing for Agriculture: An Overview“, $3^{\text {rd }}$ National Conference on Agro-Informatics and Precision Agriculture (AIPA), Aug. 2012. [Online]. Available: https://www.researchgate.net/ profile/Rangaswamy-Madugundu [Accessed: 23 Jul. 2020].

[16] Rajaraman, V. (2014) "Cloud Computing“, Resonance-Journal of Science Education, Vol. 19, No. 3, pp. 242-258. ISSN 0971-8044. DOI 10.1007/s12045-014-0030-1.

[17] Schalk, Ch. (2010) "Google Cloud Technologies Overview", Presentation of the $7^{\text {th }}$ International Cloud Expo, Nov. 2010. [Online]. Available: https:/www.slideshare.net/cschalk/google-cloudtechnologies-overview/ [Accessed: 23 Dec. 2020].

[18] Sui, X. and Sui, Y. (2018) "A Summary of Cloud Computing and Its Technology Research", $8^{\text {th }}$ International Conference on Management and Computer Science (ICMCS 2018), Vol. 77, pp. 176-179. ISSN 2352-538X. DOI 10.2991/icmcs-18.2018.35.

[19] Štětka, M. (2014) "Zálohování v cloudu a disaster recovery pro malé a střední podniky“, Časopis IT Systems - Small Business Solutions I 2014, [Online]. Available: https://www.systemonline.cz/itsecurity/zalohovani-v-cloudu-a-disaster-recovery.htm [Accessed: 23 Jul. 2020]. (In Czech).

[20] Tan, L. (2016) "Cloud-based Decision Support and Automation for Precision Agriculture in Orchards", $5^{\text {th }}$ IFAC Conference on Sensing, Control and Automation Technologies for Agriculture (AGRICONTROL), Vol. 49, No. 16, pp. 330 -335. ISSN 2405-8963. DOI 10.1016/j.ifacol.2016.10.061. 
[21] Szabo L., Romanova A., Bolek V. and Zelina M. (2017) "Intensity of ICT use by managers of agricultural enterprises“, Agricultural Economics, Vol. 63, No. 11, pp. 485-492. ISSN 0139-570X. DOI 10.17221/132/2016-AGRICECON.

[22] Wang, W. Y. Ch., Rashid, A. and Chuang, H. M. (2011) "Toward the Trend of Cloud Computing“, Journal of Electronic Commerce Research, Vol. 12, No. 4., pp. 238-242. ISSN 1526-6133.

[23] Wazzan, M. and Fayoumi, A. (2012) "A Survey of Researches on the Challenge Issues In Cloud Computing“, Information - an International Interdisciplinary Journal, Vol. 15, No. 10, pp. 4245 - 4254. ISSN 1343-4500. 